\title{
Clinical risk scores as predictors of severe outcome in hospitalized influenza patients: an observational cohort study from Norway 2014-2018
}

\author{
Torgun Wæhre ${ }^{1}$, Gro Tunheim ${ }^{2}$, Johanna Bodin ${ }^{2}$, Ida Laake ${ }^{2}$, Dag Kvale ${ }^{3}$, Anne-Marte \\ Kran $^{1}$, Hanne Brekke ${ }^{1}$, Ragnhild Løken ${ }^{1}$, Fredrik Oftung ${ }^{2}$, siri Mjaaland ${ }^{2}$, and Anne \\ Margarita Dyrhol Riise ${ }^{3}$ \\ ${ }^{1}$ Oslo University Hospital \\ ${ }^{2}$ Norwegian Institute of Public Health \\ ${ }^{3}$ University of Oslo Faculty of Medicine
}

October 23, 2020

\begin{abstract}
Background Seasonal influenza causes substantial numbers of hospitalizations annually, and there is a need to identify prognostic markers of clinical outcomes in hospitalized influenza patients. Methods Patients hospitalized with influenza were included during four influenza seasons (2014-2018). On admission, patients were assessed by the CRB65, CRB, SIRS and qSOFA risk scores. "Severe outcome" was defined as treatment in intensive care unit and/or all of the following three clinical parameters: pneumonia, O2 supplementation and hospital stay [?] 5days. Regression analyses were used to study effects of scores, influenza (sub)types and age on outcomes and treatment. Results A total of 156 patients with median age of 70 years were included. Patients with influenza A(H3N2) were older than those with B and A(H1N1). Older age was associated with fewer symptoms. Severe outcome was observed in $22 \%$ of the cases. High CRB, CRB65, SIRS and qSOFA scores at admission was observed in $60 \%, 46 \%, 40 \%$ and $29 \%$ of patients with severe outcome, respectively. Influenza (sub)types were not associated with severe outcome. Antiviral treatment was given to $37 \%$ of the patients, while $78 \%$ received antibiotics. The use of antiviral treatment increased during the study period. Patients with influenza B received less antiviral treatment. Conclusion This is the first study describing adult patients hospitalized with seasonal influenza in Norway. Risk scores, and particularly CRB, may be useful to predict severe outcome in influenza disease. More patients might have profited from antiviral therapy; including patients with influenza B infection.
\end{abstract}

Full title: Clinical risk scores as predictors of severe outcome in hospitalized influenza patients: an observational cohort study from Norway 2014-2018

Short title:Influenza hospitalizations in Norway 2014-2018

Torgun Wæhre ${ }^{*}, 1,2$ (MD, PhD), Gro Tunheim ${ }^{*}, 1,3$ (MSc, PhD), Johanna Eva Bodin ${ }^{1,3}$ (MSc, PhD), Ida Laake $^{3}(\mathrm{Msc}, \mathrm{PhD})$, Dag Kvale ${ }^{1,2,5}$ (MD, DMSc), Anne-Marte Bakken Kran ${ }^{4, \mathrm{a}}$ (MD, PhD), Hanne Brekke ${ }^{2, \mathrm{~b}}$ (MD), Ragnhild Løken ${ }^{2, \mathrm{c}}(\mathrm{MD}, \mathrm{MSc})$, Fredrik Oftung ${ }^{1,3}(\mathrm{MSc}, \mathrm{PhD})$, Siri Mjaaland ${ }^{1,3}$ (MSc, PhD), Anne Ma Dyrhol-Riise ${ }^{1,2,5}$ (MD, PhD).

Affiliation :

${ }^{*}$ These authors contributed equally to the work

${ }^{1}$ K. G. Jebsen Centre for Influenza Vaccine Research, University of Oslo and Oslo University Hospital, Oslo, Norway. 
${ }^{2}$ Department of Infectious Diseases, Oslo University Hospital, Norway

${ }^{3}$ Division of Infection Control and Environmental Health, Norwegian Institute of Public Health, Oslo, Norway

${ }^{4}$ Department of Medical Microbiology, Oslo University Hospital, Norway

${ }^{5}$ Institute of Clinical Medicine, University of Oslo, Norway

Current addresses:

${ }^{a}$ Division of Infection Control and Environmental Health. Norwegian Institute of Public Health, Oslo, Norway

${ }^{\mathrm{b}}$ Department of Medical Microbiology, Oslo University Hospital, Norway

${ }^{\mathrm{c}}$ Department of Internal Medicine, Drammen Hospital, Vestre Viken Hospital Trust, Norway

\title{
Acknowledgements:
}

We thank the patients that participated in this study. We also wish to thank the staff at the Department of Infectious Diseases, Oslo University Hospital for handling of biological samples and laboratory analyses. The study was funded by the K.G. Jebsen Centre for Influenza Vaccine Research and Oslo University Hospital.

\begin{abstract}
Background

Seasonal influenza causes substantial numbers of hospitalizations annually, and there is a need to identify prognostic markers of clinical outcomes in hospitalized influenza patients.

\section{Methods}

Patients hospitalized with influenza were included during four influenza seasons (2014-2018). On admission, patients were assessed by the CRB65, CRB, SIRS and qSOFA risk scores. "Severe outcome" was defined as treatment in intensive care unit and/or all of the following three clinical parameters: pneumonia, O2 supplementation and hospital stay [?] 5days. Regression analyses were used to study effects of scores, influenza (sub)types and age on outcomes and treatment.
\end{abstract}

\section{Results}

A total of 156 patients with median age of 70 years were included. Patients with influenza A(H3N2) were older than those with B and $\mathrm{A}(\mathrm{H} 1 \mathrm{~N} 1)$. Older age was associated with fewer symptoms. Severe outcome was observed in $22 \%$ of the cases. High CRB, CRB65, SIRS and qSOFA scores at admission was observed in $60 \%, 46 \%, 40 \%$ and $29 \%$ of patients with severe outcome, respectively. Influenza (sub)types were not associated with severe outcome. Antiviral treatment was given to $37 \%$ of the patients, while $78 \%$ received antibiotics. The use of antiviral treatment increased during the study period. Patients with influenza B received less antiviral treatment.

\section{Conclusion}

This is the first study describing adult patients hospitalized with seasonal influenza in Norway. Risk scores, and particularly $\mathrm{CRB}$, may be useful to predict severe outcome in influenza disease. More patients might have profited from antiviral therapy; including patients with influenza B infection.

Keywords: Influenza, influenza subtype, antiviral, antibiotic, severity, clinical score, hospitalization, pneumonia

\section{Introduction}

Seasonal influenza is responsible for a substantial number of hospitalizations worldwide with high morbidity and mortality, particularly among the elderly $(1,2)$. In Norway, approximately 2500 patients are hospitalized 
with influenza each season, giving an average seasonal incidence rate of 48 hospitalizations per 100000 inhabitants (3). The World Health Organization (WHO) has defined that persons above 65 years, pregnant women and persons with chronic medical or immunosuppressive conditions are at greater risk of severe influenza disease or complications (1).

Two subtypes of influenza A (H1N1 and H3N2) and two lineages of influenza B (Yamagata and Victoria) have caused seasonal influenza during the last decade (1). While still under debate, influenza B has been suggested to cause less severe disease than the A subtypes (4-6). Whether various influenza types and subtypes are responsible for different clinical features is not clear, but influenza $\mathrm{A}(\mathrm{H} 3 \mathrm{~N} 2)$ is possibly associated with severe disease in persons above 65 years, whereas influenza $\mathrm{A}(\mathrm{H} 1 \mathrm{~N} 1)$ and $\mathrm{B}$ may affect younger persons (7-9).

Pneumonia in the setting of influenza disease occurs frequently and can be caused by the influenza virus itself or by bacteria such asStreptococcus pneumonia and Staphylococcus aureus (10). The discrimination between solitary viral pneumonia and pneumonia with bacterial coinfections is difficult. Thus, hospitalized influenza patients often receive antibiotic treatment, even when there is no obvious evidence of bacterial coinfections, possibly leading to unnecessary use of antibiotics $(10,11)$. In contrast, while international guidelines recommend that antiviral treatment with neuraminidase inhibitors always should be considered in patients hospitalized with proven or suspected influenza, such therapy may be underused (12-14).

As far as we are aware, there are no previous studies characterizing adult patients hospitalized with seasonal influenza in Norway. In this study we included patients hospitalized with influenza at a large university hospital between 2014 and 2018.

Our primary aim was to investigate whether established clinical risk score systems could predict severe outcome. Moreover, we also studied whether age and influenza types/subtypes (from here called (sub)types)) was associated with symptoms, risk scores, clinical outcomes and antimicrobial treatment.

\section{Methods}

\section{Study setting, patients and inclusion}

The study was conducted at Oslo University Hospital, Norway, during the four consecutive influenza seasons 2014-15 (S1), 2015-16 (S2), 2016-17 (S3) and 2017-18 (S4).

Patients [?] 18 years, with community-acquired influenza confirmed by in house influenza virus A/B RNA Real Time-PCR, were included within the first 3 days of hospitalization. There were no exclusion criteria.

\section{Clinical data and scoring of disease severity}

Patient data was collected by their respective physicians through patient interviews and from medical records. Patient characteristics, predisposing conditions (Table 1) and self-reported influenza vaccination status from the current season were recorded.

Nine influenza-specific self-reported symptoms were recorded (Table 2). We documented C-reactive protein (CRP) levels, radiological infiltrates on chest x-rays suggestive of pneumonia on admission (here defined as pneumonia), microbial findings from airway samples (nasopharyngeal swabs, sputum) and blood cultures. Diagnostics of respiratory pathogens in addition to influenza virus included bacterial cultures and in-house PCR panels for other respiratory viruses. Samples with detected influenza virus A were further analyzed with subtype-specific PCR to determine subtype H1 or H3. Further, treatment in ICU, need of oxygen supplementation, duration of hospital stay and antiviral and antibiotic treatment during hospital stay were registered.

The following four clinical risk scores were recorded at admission;

1) $\mathrm{C}$ onfusion, $\mathrm{r}$ espiratory rate, $\mathrm{b}$ lood pressure and age [?]65 years (CRB65) score; rewarding one point to each of the following signs: c onfusion, $\mathrm{r}$ espiratory rate [?]30/ min, systolic b lood pressure $<90 \mathrm{mmHg}$ or 
diastolic b lood pressure [?]60 mmHg, and age[?]65 years (15). CRB65 [?] 2 points were defined as severe disease $\left(\mathrm{CRB} 65^{\text {high }}\right)(15,16)$.

2) CRB; a modified CRB65 with no points for age. CRB [?]1 was defined as severe disease $\left(\mathrm{CRB}^{\text {high }}\right)$.

3) S ystemic I nflammatory R esponse S yndrome (SIRS) score, rewarding one point to each of the following signs: Temperature $>38 \mathrm{degC}$ or $<36 \mathrm{degC}$, heart rate $>90$ beats $/ \mathrm{min}$, respiratory $>20 / \mathrm{min}$, leucocytes $>$ $12,000 / \mu \mathrm{L}$ or $<4000 / \mu \mathrm{L}$. SIRS [?] 3 points was defined as severe disease (SIRS $\left.{ }^{\text {high }}\right)(17)$.

4) The q uick $\mathrm{S}$ equential $\mathrm{O}$ rgan $\mathrm{F}$ ailure $A$ ssessment (qSOFA) score, with one point for the following clinical signs: altered mental status, respiratory rate [?]22/ min, systolic blood pressure [?]100 $\mathrm{mmHg}$ (18). qSOFA [?]2 points were defined as severe disease (qSOFA $\left.{ }^{\text {high }}\right)$.

Severe outcome of influenza as a combined clinical endpoint was defined as receiving treatment in ICU and/ or having all of the following three factors: Pneumonia on admission and oxygen supplementation during the hospital stay and staying in hospital [?]5 days.

\section{Statistics}

Differences in symptoms, clinical findings, severity scores, clinical outcomes and microbial treatment according to age, sex and influenza (sub)types were analyzed using Mann-Whitney U and Wilcoxon rank-sum tests for continuous variables, and Chi square test for categorical variables. We also used logistic regression to estimate odds ratios (ORs) with corresponding 95\% confidence intervals (CIs) to study relevant exposures in relation to the various binary clinical outcomes or microbial treatment. For continuous variables, such as CRP and age, we used linear regression. All regression analyses were adjusted for age (except CRB65 scores), sex and having [?]2 predisposing conditions. Statistical analyses were performed with Stata/SE 15.0.

\section{Ethics}

The study was approved by The Regional Committee for Medical and Health Research Ethics in South Eastern Norway (Case number 2013/2033). Written informed consent was obtained from all participants before inclusion.

\section{Results}

\section{Study participants}

Patient characteristics and the distribution of influenza (sub)types are shown in Table 1. Overall, 156 patients (52.6\% women) were included during the four influenza seasons from 2014-2018 (Seasons 1-4, respectively). The patients' median age was 70 year, $59.6 \%$ were 65 years or above. Predisposing conditions were common, $78.2 \%$ of patients had at least one predisposing condition, and $43.6 \%$ had [?]2 predisposing conditions. In contrast, only 21 patients $(13.5 \%)$ were younger than 65 years and without any known predisposing conditions.

$51(32.7 \%)$ of the patients self-reported having received an influenza vaccine during the season they were hospitalized. Patients above 65 years were more often vaccinated $(39.8 \%)$ as compared to patients below 65 years $(22.2 \%$; $=0.02)$.

Overall, most of the included patients had influenza A(H3N2) (52.6\%), followed by influenza B (32.6\%) and influenza $\mathrm{A}(\mathrm{H} 1 \mathrm{~N} 1)$ (12.8\%). Three patients had influenza A of unspecified subtype (Table 1). In season 1 and season 3, most patients had influenza $\mathrm{A}(\mathrm{H} 3 \mathrm{~N} 2)$, while influenza $\mathrm{A}(\mathrm{H} 1 \mathrm{~N} 1)$ dominated among the included patients in season 2 , and influenza $\mathrm{B}$ in season 4. 


\section{Clinical presentation and scores}

The occurrence of self-reported symptoms before to hospitalization, and clinical risk scores on admission, and differences between older patients ([?]65 years) and younger patients ( $<65$ years) are shown in Table 2. Cough $(93.0 \%)$ and fever $(76.9 \%)$, were the most commonly reported symptoms. Older patients reported less fever, sore throat and headache than younger patients. The number of reported symptoms was lower and reporting [?]5 symptoms were less frequent in older than in younger patients. The median duration of self-reported symptoms before admission was 3 days. Women reported more symptoms (median 6 , range $2-9)$, than men (median 5 , range 1-9) $(\mathrm{p}=0.017)$, and headache was the only specific symptom reported more often in women $(63.4 \%)$ than men $(40.5 \%)(\mathrm{p}=0.004)$.

About $1 / 3^{\text {rd }}(34.6 \%)$ of the patients had a high CRB score, while CRB65 high, SIRShigh, and qSOFA ${ }^{\text {high }}$ were less common (Table 2). No patients below 65 year of age had CRB65 ${ }^{\text {high }}$, otherwise, the scores were comparable between the two age groups.

\section{Biochemistry and microbiology}

CRP on admission ranged from 0.6 to $316.0 \mathrm{mg} / \mathrm{L}$, with a median of $42.5 \mathrm{mg} / \mathrm{L}$.

Possible airway pathogen bacteria suggesting co-infections were found in 55 of the 150 patients (36.7\%) with airway samples. Streptococcus pneumoniae was the most frequent bacteria found in 19 of the 150 patients (12.7\%), followed by Moraxella catharralis (12.0\%),Haemophilus influenzae (8.0\%), and Staphylococcus aureus $(6.0 \%)$. Other respiratory viruses than the index influenza virus were detected in airway samples from nine of the patients $(5.8 \%)$, most frequently, respiratory syncytial virus which was found in four patients. Blood cultures were sampled from $136(87.2 \%)$ of the patients, none of these were positive.

\section{Clinical outcomes}

A total of 35 patients $(22.4 \%)$ had the combined severe outcomeaccording to our definition (Table 3$)$. Of these, nine patients $(5.8 \%)$ were treated in ICU, pneumonia was found in $46.8 \%, 43.0 \%$ received oxygen supplementation during their hospital stay and $47.4 \%$ stayed in hospital [?] 5 days. In general, patients with severe outcome were older than the rest (median age 75 vs 69 , respectively, $\mathrm{p}=0.006$ ) and were more likely to have cardiovascular disease, immunosuppression and [?]2 predisposing conditions (data not shown). Also, patients withsevere outcome were significantly more likely to report dyspnoea and less likely to report sore throat, muscle pain and [?]5 symptoms (data not shown).

In multivariate analyses, older age, bacterial findings in airway samples and high CRP levels on admission were all associated withsevere outcome (Table 3).

For the individual outcome factors, bacterial findings and high CRP levels were associated with pneumonia (Table 3). Older age, high CRP levels and female sex were associated with receiving oxygen during the hospital stay, and older age was associated with staying [?]5 days in hospital.

For all the risk scores, a high score on admission was associated withsevere outcome in these influenza patients (Table 3). Among the patients classified with severe outcome, $60.0 \%$ had $\mathrm{CRB}^{\text {high }}, 45.7 \%$ had CRB $65^{\text {high }}, 40.0 \%$ had SIRS ${ }^{\text {high }}$, and $28.6 \%$ had qSOFA ${ }^{\text {high }}$ on admission.

For the individual outcome factors, $\mathrm{CRB}^{\text {high }}$ and $\mathrm{CRB} 65^{\text {high }}$ were associated with treatment in ICU, pneumonia and oxygen supplementation. SIR ${ }^{\text {high }}$ was associated with pneumonia and oxygen supplementation, but not with ICU treatment. CRB65 $5^{\text {high }}$ was the only score associated with hospital stay [?] 5 days, possibly because all of these patients were [?]65 years old. qSOFA ${ }^{\text {high }}$ was only associated withsevere outcome, and not with any of the single factors. 


\section{Influenza (sub)types}

Patients with influenza $\mathrm{A}(\mathrm{H} 3 \mathrm{~N} 2)$ were significantly older (median age 72 years) than those with influenza $\mathrm{B}$ (median 64 years, $\mathrm{p}=0.032$ ) and influenza $\mathrm{A}(\mathrm{H} 1 \mathrm{~N} 1)$ (median age 55 years, $\mathrm{p}=0.025)$. The frequency of symptoms according to influenza (sub)types is shown in Fig. 1A. Cough was more common in patients with influenza $B$ and $A(H 3 N 2)$ than in patients with influenza $A(H 1 N 1)$. Patients with influenza $B$ were more likely to report a sore throat than patients with influenza $\mathrm{A}(\mathrm{H} 3 \mathrm{~N} 2)$ and more rhinorrhea than patients with $\mathrm{A}(\mathrm{H} 1 \mathrm{~N} 1)$. These differences in symptom presentation between influenza subtypes were preserved in multivariate regression analysis (Supplementary table 1). Patients with influenza B tended to be more likely to report [?] 5 symptoms than patients with $\mathrm{A}(\mathrm{H} 3 \mathrm{~N} 2)$ or $\mathrm{A}(\mathrm{H} 1 \mathrm{~N} 1)$ (Fig 1A and Supplementary table 1).

We found no significant differences in the risk scores CRB, qSOFA and SIRS between influenza (sub)types (Fig. 1B). More patients with influenza A(H3N2) had CRB65 high compared to patients with influenza B $(\mathrm{p}=0.002)$ and influenza $\mathrm{A}(\mathrm{H} 1 \mathrm{~N} 1)(\mathrm{p}=0.042)$. However, with multiple regression analyses the difference in CRB65 score between A(H1N1) and A(H3N2) no longer appeared (Supplementary table 2).

Notably, neither the proportion of patients with our definition ofsevere outcome nor with pneumonia, oxygen supplementation or hospital stay [?]5days differed between influenza (sub)types. Similar results were found in multivariate regression analysis (Supplementary table 3). Influenza A(H3N2) was the only (sub)type found in patients admitted to ICU ( $=9)$ (Fig 1C).

\section{Antimicrobial treatment}

During their hospital stay, $37.2 \%$ patients received antiviral treatment, all with oseltamivir (Table 4). $77.6 \%$ received antibacterial therapy and 49 patients $(31.4 \%)$ received both type of treatments. Among patients with severe outcome, $40.0 \%$ received antiviral therapy and $91.4 \%$ received antibiotics. Benzylpenicillin was the most common initial antibiotic, given to $57.7 \%$ patients, in 14 of these in combination with gentamicin. In contrast, only $8.3 \%$ patients received a second or third generation cephalosporin. In multivariate regression analysis, patients with higher CRP levels and bacterial findings in airway samples on admission received more antibiotics (Table 4).

Patients with SIRS ${ }^{\text {high }}$ were more likely to receive antivirals than patients with low SIRS scores. Patients with CRB65 $5^{\text {high }}$, qSOFA ${ }^{\text {high }}$ and SIRS ${ }^{\text {high }}$ at admission tended to receive more antibiotics than patients with corresponding low scores, but the differences were not significant.

Patients defined as having severe outcome, were more likely to receive antibiotics, but not antivirals (Table 4). There was a trend that ICU treatment was associated with receiving antiviral therapy, but not with antibiotic treatment. Patients with pneumonia, or who received oxygen supplementation, or who stayed [?]5 days in hospital, received significantly more antibiotics, while no such differences were found for antivirals.

The use of antiviral treatment was significantly higher in season $3(51.4 \%)$ than in season 1 (22.0\%) (Fig. 2A and Supplementary table 4). The use of antibiotics was constant during the four seasons. Patients with influenza $\mathrm{A}(\mathrm{H} 3 \mathrm{~N} 2)$ received more antivirals than patients with influenza B (46.3\% vs $25.5 \%$, respectively (Fig 2B), and such an association was also found with multivariate regression analysis (supplementary table $4)$, also after additional adjustment for season $(\mathrm{p}=0.009)$. However, we observed no differences in antibiotic prescription between the influenza (sub)types.

\section{Discussion}

Here, we present clinical and microbiological characteristics and prognostic risk scores for severe outcome in adult hospitalized influenza patients during four consecutive influenza seasons $2014-2018$. About 85\% of the patients were in a high-risk group for complicated influenza disease because of age and/or predisposing medical conditions. About one in four patients had clinical risk scores on admission indicating severe disease, and $22 \%$ had severe outcome according to our definition. The clinical score CRB $^{\text {high }}$ showed the best 
prediction for severe clinical outcome in these influenza patients irrespective of age, and seemed preferable to SIRS and qSOFA commonly used in clinical practice.

To study outcomes of influenza disease in hospitalized patients, different parameters such as in-hospital mortality, treatment in ICU, superinfections with pneumonia or other complications, and length of hospital stay have been used $(6-9,19,20)$. Our definition of "severe outcome" may be debatable. The aim was to correctly identify patients that from a clinical perspective truly suffered from severe disease, and it is our opinion that having pneumonia, requiring oxygen or needing ICU treatment are clinical markers of severity.

Clinical scorings systems are frequently used to evaluate severe infections like community acquired pneumoniae and suspected sepsis $(15,18)$. To our knowledge, there are no established clinical scores for assessing disease severity at admission in hospitalized influenza patients. Scoring systems validated for evaluation of community-acquired pneumonia such as the pneumonia severity index (PSI) and the CURB65 score (a variant of CRB65 where levels of P-urea is also included) seem to have shown variable utility in prediction of outcome in hospitalized influenza patients $(11,21,22)$. In present study, we found that high scores of CRB, CRB65, SIRS and qSOFA on admission were associated with severe outcome. Moreover, for patients with severe outcome, a high CRB score was found more frequently than any of the other high scores. Thus, we suggest that clinical severity scores, especially age-independent CRB, might be useful for the initial assessment and prediction of risk forsevere outcome in patients hospitalized with influenza.

In the present study, influenza $\mathrm{A}(\mathrm{H} 3 \mathrm{~N} 2)$ was diagnosed in approximately half of the patients for the whole period with a predominance in the season 2016-2017. The influenza (sub)type distribution coincided with the virus (sub)types circulating in Norway and in Europe in the same time periods $(1,7,8,23)$.

In our patient population, comorbid conditions, especially cardiovascular and pulmonary diseases, were frequent, and the patients were also older than the participants in other recent studies with hospitalized influenza patients $(5,8,9,11,19)$. We found that patients infected with influenza $\mathrm{A}(\mathrm{H} 3 \mathrm{~N} 2)$ were significantly older than patients with influenza $\mathrm{B}$, while the patients with $\mathrm{A}(\mathrm{H} 1 \mathrm{~N} 1)$ were the youngest. This age distribution pattern has also been reported by others $(7,8,19)$. In studies comparing patients with influenza A with influenza B without discriminating between the A subtypes, no age differences were reported $(5,6)$. It is not known why the elderly population seems to be more at risk for infection with influenza A(H3N2). However, combined effects of aging of the immune system (immunosenescence), influenza A(H3N2) virus evolving more rapidly than the other (sub)types and immune imprinting with $\mathrm{A}(\mathrm{H} 1 \mathrm{~N} 1)$ in the youth of today's elderly patients, may contribute (24-27).

Possible differences in disease severity between influenza(sub)types have been addressed in several previous studies with conflicting results $(28,29)$. In our study, we found no differences in CRB, SIRS and qSOFA scores between the influenza (sub)types. Patients with influenza A(H3N2) tended to have higher CRB65 scores on admission than patients with influenza B and $\mathrm{A}(\mathrm{H} 1 \mathrm{~N} 1)$, possibly explained with more $\mathrm{A}(\mathrm{H} 3 \mathrm{~N} 2)$ patients being older than 65 years. When studying the various clinical outcomes no differences between influenza (sub)types were found. Contrary to this, Delgado-Sanz et al recently reported more severe outcome in patients hospitalized with $\mathrm{A}(\mathrm{H} 1 \mathrm{~N} 1)$ compared to $\mathrm{A}(\mathrm{H} 3 \mathrm{~N} 2)$ and $\mathrm{B}(7)$, while Wang et al found that hospitalized patients with influenza B had less severe disease than influenza A patients (5). Yet other studies could not confirm such differences in disease severity between influenza (sub)types $(8,19,30)$. Contradictory findings may at least partly be explained by methodological differences both in terms of patient inclusion and criteria for assessment of disease severity.

Cough and fever were the most common self-reported symptoms in our patient population, as observed in other studies in hospitalized influenza patients $(6,11,19,31)$. Patients above 65 years reported fewer influenza-suggestive symptoms than the younger patients, supporting that elderly patients present with a less specific clinical picture of influenza disease $(19,31,32)$. In agreement with a previous study, women reported more numerous symptoms than men (31). For symptom presentation we found small differences between the influenza (sub)types, with influenza B patients reporting more cough and rhinorrhea than A(H1N1), and more sore throat than $\mathrm{A}(\mathrm{H} 3 \mathrm{~N} 2)$ patients. Other authors have reported less fever and more rhinorrhea in 
patients with influenza B than influenza A (sub)types $(6,9,33)$. These data could suggest that influenza B may cause more "common cold" symptoms than the A subtypes; however, the clinical implications of these possible differences are uncertain, and several other studies could not find such differences (28).

Antibiotic therapy was given to almost $80 \%$ of our patient population, which corresponds well with previous studies on hospitalized influenza patients $(11,31)$. Clinical assessments using scoring systems could possibly be useful to guide antibiotic treatment in influenza patients. In our study, patients with high scores of CRB65, qSOFA and SIRS on admission tended to have more antibiotic treatment. We found that antibiotic treatment was also more frequent in patients withsevere outcome, pneumonia, receiving oxygen supplementation or having higher CRP levels, or bacterial findings in airway samples, all factors that are indicative of bacterial coinfections. While CRP is a widely used biomarker to possibly discriminate between bacterial and viral infection, in the setting of influenza disease CRP discriminates poorly between pure viral and bacterial coinfections $(34,35)$. In contrast to findings in other studies, a majority of our patients received the narrow-spectrum antibiotic benzylpenicillin, reflecting the relatively restrictive recommendations for antibiotic prescription in the national guidelines, and relatively low level of antibiotic resistance in Norway (36).

Based on evidence from randomized and observational studies, international guidelines recommend antiviral treatment for all hospitalized patients with suspected or proven influenza disease $(13,37)$. In our study, less than $40 \%$ of the patients received antiviral therapy. Other studies from the same time period have shown a great variation of antiviral prescription rates in hospitalized patients, ranging from 12 to $93 \%$ (6-8, 19, 30 ). We found a trend of increasing use of antivirals from the 2014/15 and 2015/16 seasons to the 2016/17 season, suggesting increasing awareness of the beneficial effect of this treatment during the study period. We did not find any associations between prescription of antivirals and severe outcome, nor with the diagnosis of pneumonia or need of oxygen supplementation, indicating too little use of antivirals in this time period. Interestingly, we found that patients with influenza B received less antiviral therapy than patients with the influenza A subtypes. Similar differences were also reported in other studies $(7,30)$. However, as oseltamivir is approved for treatment of both influenza A and B and antivirals were part of the recommended therapy for all hospitalized influenza patients at the time of the study start, the reason for this difference is unclear. However, the observation could possibly be explained by patients with influenza A(H3N2) being older and probably more fragile with lower threshold for an aggressive therapeutic approach.

A strength of this study is that all patients had PCR-confirmed influenza. We also present the results adjusted for age, sex and having [?]2 predisposing factors, as adjusted results are lacking in many studies on influenza (sub)types and severity (28). Moreover, to our knowledge, this is the first study from Norway describing the clinical picture in adults hospitalized with seasonal influenza. By including patients over several seasons, we could study possible differences between influenza caused by different (sub)types and potential changes in antimicrobial treatment with time.

Our study has several limitations. First, few patients with influenza A(H1N1) were included, reducing the statistical power to explore differences between this (sub)type and the others. Second, we did not discriminate between the influenza B lineages Victoria and Yamagata, which may differ in their clinical presentation and severity (28). Third, the study was not designed to evaluate outcomes such as in-hospital and 30 days mortality. Forth, we were not able to include all the patients that were admitted to the hospital over the four seasons.

In conclusion, the patients in our study were elderly and/or with conditions predisposing for severe influenza infection. Clinical scoring systems seem to be useful to predict severe outcome, with the age-independent score CRB showing the most potential in this type of patients. The different influenza (sub)types were not associated with differences in clinical outcomes but we observed more influenza A(H3N2) in older than in younger individuals. There may have been an underuse of antiviral treatment in our patient population. 


\section{References}

1. Influenza (seasonal): World Health Assosiation; 2018 [Available from:https://www.who.int/en/newsroom/fact-sheets/detail/influenza-(seasonal).

2. Gran JM, Iversen B, Hungnes O, Aalen OO. Estimating influenza-related excess mortality and reproduction numbers for seasonal influenza in Norway, 1975-2004. Epidemiology and infection. 2010;138(11):1559-68.

3. Hauge SH, Bakken IJ, de Blasio BF, Haberg SE. Burden of medically attended influenza in Norway 2008-2017. Influenza and other respiratory viruses. 2019;13(3):240-7.

4. Su S, Chaves SS, Perez A, D'Mello T, Kirley PD, Yousey-Hindes K, et al. Comparing clinical characteristics between hospitalized adults with laboratory-confirmed influenza A and B virus infection. Clin Infect Dis. 2014;59(2):252-5.

5. Wang Y, Fan G, Horby P, Hayden F, Li Q, Wu Q, et al. Comparative Outcomes of Adults Hospitalized With Seasonal Influenza A or B Virus Infection: Application of the 7-Category Ordinal Scale. Open forum infectious diseases. 2019;6(3):ofz053.

6. Cohen R, Babushkin F, Geller K, Finn T. Characteristics of hospitalized adult patients with laboratory documented Influenza A, B and Respiratory Syncytial Virus - A single center retrospective observational study. PloS one. 2019;14(3):e0214517.

7. Delgado-Sanz C, Mazagatos-Ateca C, Oliva J, Gherasim A, Larrauri A. Illness Severity in Hospitalized Influenza Patients by Virus Type and Subtype, Spain, 2010-2017. Emerging infectious diseases. 2020;26(2):2208.

8. Martinez A, Soldevila N, Romero-Tamarit A, Torner N, Godoy P, Rius C, et al. Risk factors associated with severe outcomes in adult hospitalized patients according to influenza type and subtype. PloS one. 2019;14(1):e0210353.

9. Wie SH, So BH, Song JY, Cheong HJ, Seo YB, Choi SH, et al. A comparison of the clinical and epidemiological characteristics of adult patients with laboratory-confirmed influenza A or B during the 20112012 influenza season in Korea: a multi-center study. PloS one. 2013;8(5):e62685.

10. Blyth CC, Webb SA, Kok J, Dwyer DE, van Hal SJ, Foo H, et al. The impact of bacterial and viral co-infection in severe influenza. Influenza and other respiratory viruses. 2013;7(2):168-76.

11. Akers IE, Weber R, Sax H, Boni J, Trkola A, Kuster SP. Influence of time to diagnosis of severe influenza on antibiotic use, length of stay, isolation precautions, and mortality: a retrospective study. Influenza and other respiratory viruses. 2017;11(4):337-44.

12. Clark TW, Medina MJ, Batham S, Curran MD, Parmar S, Nicholson KG. Adults hospitalised with acute respiratory illness rarely have detectable bacteria in the absence of COPD or pneumonia; viral infection predominates in a large prospective UK sample. The Journal of infection. 2014;69(5):507-15.

13. Uyeki TM, Bernstein HH, Bradley JS, Englund JA, File TM, Fry AM, et al. Clinical Practice Guidelines by the Infectious Diseases Society of America: 2018 Update on Diagnosis, Treatment, Chemoprophylaxis, and Institutional Outbreak Management of Seasonal Influenzaa. Clinical infectious diseases : an official publication of the Infectious Diseases Society of America. 2019;68(6):e1-e47.

14. Wolkewitz M, Schumacher M. Neuraminidase Inhibitors and Hospital Mortality in British Patients with H1N1 Influenza A: A Re-Analysis of Observational Data. PloS one. 2016;11(9):e0160430.

15. Bauer TT, Ewig S, Marre R, Suttorp N, Welte T. CRB-65 predicts death from community-acquired pneumonia. Journal of internal medicine. 2006;260(1):93-101.

16. Lim WS, van der Eerden MM, Laing R, Boersma WG, Karalus N, Town GI, et al. Defining community acquired pneumonia severity on presentation to hospital: an international derivation and validation study. 
Thorax. 2003;58(5):377-82.

17. Bone RC, Balk RA, Cerra FB, Dellinger RP, Fein AM, Knaus WA, et al. Definitions for sepsis and organ failure and guidelines for the use of innovative therapies in sepsis. The ACCP/SCCM Consensus Conference Committee. American College of Chest Physicians/Society of Critical Care Medicine. Chest. 1992;101(6):1644-55.

18. Seymour CW, Liu VX, Iwashyna TJ, Brunkhorst FM, Rea TD, Scherag A, et al. Assessment of Clinical Criteria for Sepsis: For the Third International Consensus Definitions for Sepsis and Septic Shock (Sepsis-3). Jama. 2016;315(8):762-74.

19. Loubet P, Samih-Lenzi N, Galtier F, Vanhems P, Loulergue P, Duval X, et al. Factors associated with poor outcomes among adults hospitalized for influenza in France: A three-year prospective multicenter study. Journal of clinical virology : the official publication of the Pan American Society for Clinical Virology. 2016;79:68-73.

20. Mohn KG, Cox RJ, Tunheim G, Berdal JE, Hauge AG, Jul-Larsen A, et al. Immune Responses in Acute and Convalescent Patients with Mild, Moderate and Severe Disease during the 2009 Influenza Pandemic in Norway. PloS one. 2015;10(11):e0143281.

21. Mulrennan S, Tempone SS, Ling IT, Williams SH, Gan GC, Murray RJ, et al. Pandemic influenza (H1N1) 2009 pneumonia: CURB-65 score for predicting severity and nasopharyngeal sampling for diagnosis are unreliable. PloS one. 2010;5(9):e12849.

22. Riquelme R, Jimenez P, Videla AJ, Lopez H, Chalmers J, Singanayagam A, et al. Predicting mortality in hospitalized patients with $2009 \mathrm{H} 1 \mathrm{N1}$ influenza pneumonia. The international journal of tuberculosis and lung disease : the official journal of the International Union against Tuberculosis and Lung Disease. 2011;15(4):542-6.

23. Årsrapporter for influensa: Norwegian institute of public health; 2019 [Available from:https://www.fhi.no/sv/influensa/influensaovervaking/arsrapporter/.

24. Ferguson NM, Galvani AP, Bush RM. Ecological and immunological determinants of influenza evolution. Nature. 2003;422(6930):428-33.

25. Gostic KM, Bridge R, Brady S, Viboud C, Worobey M, Lloyd-Smith JO. Childhood immune imprinting to influenza A shapes birth year-specific risk during seasonal H1N1 and H3N2 epidemics. PLoS pathogens. 2019;15(12):e1008109.

26. Lessler J, Riley S, Read JM, Wang S, Zhu H, Smith GJ, et al. Evidence for antigenic seniority in influenza A (H3N2) antibody responses in southern China. PLoS pathogens. 2012;8(7):e1002802.

27. Nikolich-Žugich J. The aging immune system: challenges for the 21st century. Seminars in immunology. 2012;24(5):301-2.

28. Caini S, Kroneman M, Wiegers T, El Guerche-Seblain C, Paget J. Clinical characteristics and severity of influenza infections by virus type, subtype, and lineage: A systematic literature review. Influenza and other respiratory viruses. 2018;12(6):780-92.

29. Thompson WW, Shay DK, Weintraub E, Brammer L, Cox N, Anderson LJ, et al. Mortality associated with influenza and respiratory syncytial virus in the United States. Jama. 2003;289(2):179-86.

30. Chagvardieff A, Persico N, Marmillot C, Badiaga S, Charrel R, Roch A. Prospective comparative study of characteristics associated with influenza A and B in adults. Medecine et maladies infectieuses. 2018;48(3):180-7.

31. Babcock HM, Merz LR, Fraser VJ. Is influenza an influenza-like illness? Clinical presentation of influenza in hospitalized patients. Infect Control Hosp Epidemiol. 2006;27(3):266-70. 
32. Falsey AR, Baran A, Walsh EE. Should clinical case definitions of influenza in hospitalized older adults include fever? Influenza and other respiratory viruses. 2015;9 Suppl 1:23-9.

33. Gutierrez-Pizarraya A, Perez-Romero P, Alvarez R, Aydillo TA, Osorio-Gomez G, Milara-Ibanez C, et al. Unexpected severity of cases of influenza B infection in patients that required hospitalization during the first postpandemic wave. The Journal of infection. 2012;65(5):423-30.

34. Haran JP, Beaudoin FL, Suner S, Lu S. C-reactive protein as predictor of bacterial infection among patients with an influenza-like illness. The American journal of emergency medicine. 2013;31(1):137-44.

35. Ingram PR, Inglis T, Moxon D, Speers D. Procalcitonin and C-reactive protein in severe 2009 H1N1 influenza infection. Intensive Care Med. 2010;36(3):528-32.

36. NORM NORM VET 2018. 2019.

37. Dominguez A, Romero-Tamarit A, Soldevila N, Godoy P, Jane M, Martinez A, et al. Effectiveness of antiviral treatment in preventing death in severe hospitalised influenza cases over six seasons. Epidemiology and infection. 2018:1-10.

Table 1. Patient characteristics and distribution of influenza (sub)types in included patients over the 4 consecutive influenza seasons

\begin{tabular}{|c|c|c|c|c|}
\hline & Total & Season 1 2014-15 & Season 2 2015-16 & Season 3 2016-1 \\
\hline Patients, n (\%) & $156(100)$ & $41(26.3)$ & $28(17.9)$ & $35(22.4)$ \\
\hline Females, n (\%) & $82(52.6)$ & $23(56.1)$ & $15(53.6)$ & $15(42.9)$ \\
\hline Age, median [range] & $70[18-102]$ & $74[32-95]$ & $55[25-95]$ & $71[26-102]$ \\
\hline Age [?] 65 years, $\mathrm{n}(\%)$ & $93(59.6)$ & $30(73.2)$ & $11(39.3)$ & $25(71.4)$ \\
\hline \multicolumn{5}{|l|}{ Predisposing conditions, $\mathrm{n}(\%)$} \\
\hline Cardiovascular disease & $75(48.1)$ & $25(61.0)$ & $8(28.6)$ & $20(57.1)$ \\
\hline Pulmonary disease & $54(34.0)$ & $16(39.0)$ & $6(21.4)$ & $12(34.3)$ \\
\hline Diabetes & $26(16.7)$ & $6(14.6)$ & $4(14.3)$ & $7(20.0)$ \\
\hline Immunosuppression & $21(13.5)$ & $8(19.5)$ & $4(14.3)$ & $3(8.6)$ \\
\hline Neurological disease & $18(11.5)$ & $6(14.6)$ & 0 & $6(17.1)$ \\
\hline Malignancies & $10(6.4)$ & $5(12.2)$ & $4(14.3)$ & $1(2.9)$ \\
\hline Renal disease $\left(\mathrm{GFR}<59 \mathrm{ml} / \mathrm{min} / 1.73 \mathrm{~m}^{2}\right)$ & $12(7.7)$ & $2(4.9)$ & $2(7.1)$ & $4(11.4)$ \\
\hline Obesity (BMI[?]30 kg/m²) & $8(5.1)$ & $4(9.8)$ & $2(7.1)$ & $1(2.9)$ \\
\hline Liver disease & $3(1.9)$ & 0 & $2(7.1)$ & $1(2.9)$ \\
\hline Pregnancy & $4(3.0)$ & 0 & $2(7.1)$ & $2(5.7)$ \\
\hline 1 predisposing condition & $122(78.2)$ & $35(85.4)$ & $19(67.9)$ & $30(85.7)$ \\
\hline 2 predisposing conditions & $68(43.6)$ & $24(58.5)$ & $7(25.0)$ & $18(51.4)$ \\
\hline No predisposing condition and age $<65$ year, n (\%) & $21(13.5)$ & $3(7.3)$ & $7(25.0)$ & $2(5.7)$ \\
\hline Seasonal influenza vaccination ${ }^{\mathrm{a}}, \mathrm{n}(\%)$ & $51(32.7)$ & $16(39.0)$ & $9(32.1)$ & $10(28.6)$ \\
\hline \multicolumn{5}{|l|}{ Influenza strains and subtypes, $\mathrm{n}(\%)$} \\
\hline Influenza A(H3N2) & $82(52.6)$ & $26(63.4)$ & $4(14.3)$ & $33(94.2)$ \\
\hline Influenza A(H1N1) & $20(12.8)$ & 0 & $18(64.4)$ & 0 \\
\hline Influenza A na & $3(1.9)$ & $1(2.4)$ & $1(3.6)$ & 0 \\
\hline Influenza B & $51(32.6)$ & $14(34.1)$ & $5(17.9)$ & $2(5.7)$ \\
\hline
\end{tabular}

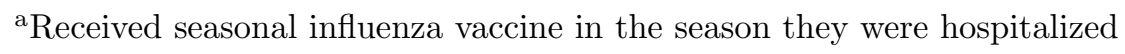

${ }^{\mathrm{b}}$ Subtype not available

Table 2. Self-reported symptoms before hospitalization and clinical risk scores on admission in patients below and [?]65 years of age 


\begin{tabular}{|c|c|c|c|c|}
\hline & Total & $<65$ years of age & [?]65 years of age & $\mathrm{P}$ value (chi2) \\
\hline Patients, n (\%) & $156(100.0)$ & $63(40.4)$ & $93(59.6)$ & - \\
\hline \multicolumn{5}{|l|}{ Self-reported symptoms } \\
\hline Cough, n $(\%)$ & $145(93.0)$ & $61(96.8)$ & $84(90.3)$ & 0.120 \\
\hline Fever $^{\mathrm{a}}, \mathrm{n}(\%)$ & $120(76.9)$ & $57(90.5)$ & $63(67.7)$ & 0.001 \\
\hline Dyspnea, n (\%) & $111(71.2)$ & $45(71.4)$ & $66(71.0)$ & 0.950 \\
\hline Muscle pain, n (\%) & $97(62.2)$ & $45(71.4)$ & $52(55.9)$ & 0.050 \\
\hline Sore throat, n (\%) & $90(57.7)$ & $45(71.4)$ & $45(48.4)$ & 0.004 \\
\hline Headache, n (\%) & $82(52.6)$ & $46(73.0)$ & $36(38.7)$ & $<0.001$ \\
\hline Rhinorrhea, n (\%) & $62(39.7)$ & $28(44.4)$ & $34(36.6)$ & 0.323 \\
\hline Chest pain, n (\%) & $55(35.3)$ & $25(39.7)$ & $30(32.3)$ & 0.341 \\
\hline Gastrointestinal, n (\%) & $37(23.7)$ & $15(23.8)$ & $22(23.7)$ & 0.982 \\
\hline Number of symptoms, median [range] & $5[1-9]$ & $6[2-9]$ & $5[1-9]$ & $0.0001^{\mathrm{b}} ? \_?$ \\
\hline 5 symptoms, n (\%) & $98(62.8)$ & $51(81.0)$ & $47(50.5)$ & $<0.001$ \\
\hline \multicolumn{5}{|l|}{ Clinical risk score at admission } \\
\hline $\mathrm{CRB}^{\text {high }}, \mathrm{n}(\%)$ & $54(34.6)$ & $19(30.2)$ & $35(37.6)$ & 0.336 \\
\hline CRB65 $5^{\text {high }}, \mathrm{n}(\%)$ & $35(22.4)$ & 0 & $35(37.6)$ & $<0.001$ \\
\hline SIRS $^{\text {high }}, \mathrm{n}(\%)$ & $39(25.0)$ & $15(23.8)$ & $24(25.8)$ & 0.777 \\
\hline qSOFA ${ }^{\text {high }}, \mathrm{n}(\%)$ & $22(14.1)$ & $7(11.1)$ & $15(16.1)$ & 0.377 \\
\hline
\end{tabular}

${ }^{a}$ Measured or subjective

${ }^{\mathrm{b}}$ Wilcoxon rank-sum test

Table 3. Clinical outcomes and associations with patient characteristics, laboratory data and clinical risk scores

Clinical outcomes

\begin{tabular}{|c|c|c|c|c|c|c|c|c|c|}
\hline & $\begin{array}{l}\text { Severe } \\
\text { out- } \\
\text { come }^{\text {a }}\end{array}$ & $\begin{array}{l}\text { Severe } \\
\text { out- } \\
\text { come }\end{array}$ & $\begin{array}{l}\text { Intensive } \\
\text { care } \\
\text { treatment }\end{array}$ & $\begin{array}{l}\text { Intensive } \\
\text { care } \\
\text { treatment }\end{array}$ & $\begin{array}{l}\text { Pneumonia } \\
\text { on } \\
\text { admission }\end{array}$ & $\begin{array}{l}\text { Pneumonia } \\
\text { on } \\
\text { admission }\end{array}$ & $\begin{array}{l}\text { Oxygen } \\
\text { supple- } \\
\text { menta- } \\
\text { tion at } \\
\text { any } \\
\text { time }\end{array}$ & $\begin{array}{l}\text { Oxygen } \\
\text { supple- } \\
\text { menta- } \\
\text { tion at } \\
\text { any } \\
\text { time }\end{array}$ & $\begin{array}{l}{[?] 5} \\
\text { days in } \\
\text { hospital }\end{array}$ \\
\hline \multirow[t]{2}{*}{$\begin{array}{l}\text { Patients, } \\
\mathrm{n}(\%)\end{array}$} & $\begin{array}{l}35 \\
(22.4)\end{array}$ & $\begin{array}{l}35 \\
(22.4)\end{array}$ & $9(5.8)$ & $9(5.8)$ & $\begin{array}{l}73 \\
(46.8)\end{array}$ & $\begin{array}{l}73 \\
(46.8)\end{array}$ & $\begin{array}{l}67 \\
(43.0)\end{array}$ & $\begin{array}{l}67 \\
(43.0)\end{array}$ & $\begin{array}{l}74 \\
(47.4)\end{array}$ \\
\hline & $\begin{array}{l}\operatorname{adjOR}^{b} \\
(95 \% \\
\text { CI })^{c}\end{array}$ & $\mathrm{P}$ value & $\begin{array}{l}\operatorname{adjOR} \\
(95 \% \mathrm{CI}) \\
\mathrm{c}\end{array}$ & $\mathrm{P}$ value & $\begin{array}{l}\operatorname{adjOR} \\
(95 \% \mathrm{CI}) \\
\mathrm{c}\end{array}$ & $\mathrm{P}$ value & $\begin{array}{l}\operatorname{adjOR} \\
(95 \% \mathrm{CI}) \\
\mathrm{c}\end{array}$ & $\mathrm{P}$ value & $\begin{array}{l}\text { adjOR } \\
(95 \% \mathrm{CI}) \\
\text { c }\end{array}$ \\
\hline \multicolumn{10}{|c|}{ characteristicharacteristicharacteristic } \\
\hline $\begin{array}{l}\text { Age } \\
{[\text { cont. }]^{\mathrm{d}}}\end{array}$ & $\begin{array}{l}1.03 \\
(1.01 \\
1.06)\end{array}$ & 0.018 & $\begin{array}{l}1.02 \\
(0.97, \\
1.06)\end{array}$ & 0.437 & $\begin{array}{l}1.01 \\
(0.99, \\
1.03)\end{array}$ & 0.180 & $\begin{array}{l}1.03 \\
(1.01, \\
1.05)\end{array}$ & 0.004 & $\begin{array}{l}1.04 \\
(1.02, \\
1.06)\end{array}$ \\
\hline Females & $\begin{array}{l}1.23 \\
(0.56, \\
2.70)\end{array}$ & 0.608 & $\begin{array}{l}0.76 \\
(0.19, \\
2.99)\end{array}$ & 0.695 & $\begin{array}{l}0.83 \\
(0.44, \\
1.57)\end{array}$ & 0.565 & $\begin{array}{l}1.99 \\
(1.00, \\
3.93)\end{array}$ & 0.049 & $\begin{array}{l}0.85 \\
(0.43, \\
1.68)\end{array}$ \\
\hline $\begin{array}{l}{[?] 2} \\
\text { predis- } \\
\text { posing } \\
\text { conditions }\end{array}$ & $\begin{array}{l}2.12 \\
(0.94 \\
4.76)\end{array}$ & 0.071 & $\begin{array}{l}2.26 \\
(0.52, \\
9.87)\end{array}$ & 0.272 & $\begin{array}{l}1.33 \\
(0.68, \\
2.60)\end{array}$ & 0.41 & $\begin{array}{l}1.63 \\
(0.81, \\
3.27)\end{array}$ & 0.17 & $\begin{array}{l}1.71 \\
(0.84, \\
3.44)\end{array}$ \\
\hline
\end{tabular}




\begin{tabular}{|c|c|c|c|c|c|c|c|c|c|}
\hline $\begin{array}{l}\text { Laboratory } \\
\text { data }\end{array}$ & $\begin{array}{l}\text { Laboratory } \\
\text { data }\end{array}$ & & & & & & & & \\
\hline $\begin{array}{l}\text { Pos. } \\
\text { bacte- } \\
\text { rial } \\
\text { airway } \\
\text { sam- } \\
\text { ples at } \\
\text { admissione }\end{array}$ & $\begin{array}{l}2.36 \\
(1.03 \\
5.41)\end{array}$ & 0.042 & $\begin{array}{l}1.70 \\
(0.99, \\
1.01)\end{array}$ & 0.462 & $\begin{array}{l}2.91 \\
(1.44, \\
5.89)\end{array}$ & 0.003 & $\begin{array}{l}1.67 \\
(0.82, \\
3.41)\end{array}$ & 0.16 & $\begin{array}{l}1.91 \\
(0.91, \\
3.99)\end{array}$ \\
\hline 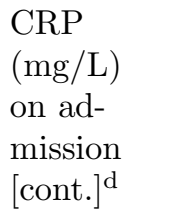 & $\begin{array}{l}1.01 \\
(1.00, \\
1.01)\end{array}$ & 0.022 & $\begin{array}{l}1.00 \\
(0.99 \\
1.01)\end{array}$ & 0.517 & $\begin{array}{l}1.02 \\
(1.01, \\
1.02)\end{array}$ & 0.001 & $\begin{array}{l}1.01 \\
(1.00, \\
1.01)\end{array}$ & 0.015 & $\begin{array}{l}1.00 \\
(1.00, \\
1.01)\end{array}$ \\
\hline $\begin{array}{l}\text { Clinical } \\
\text { risk } \\
\text { scores }\end{array}$ & $\begin{array}{l}\text { Clinical } \\
\text { risk } \\
\text { scores }\end{array}$ & $\begin{array}{l}\text { Clinical } \\
\text { risk } \\
\text { scores }\end{array}$ & & & & & & & \\
\hline $\mathrm{CRB}^{\text {high }}$ & $\begin{array}{l}3.51 \\
(1.54 \\
8.00)\end{array}$ & 0.003 & $\begin{array}{l}15.38 \\
(1.84 \\
128.96)\end{array}$ & 0.012 & $\begin{array}{l}2.57 \\
(1.28, \\
5.16)\end{array}$ & 0.008 & $\begin{array}{l}4.08 \\
(1.93, \\
8.63)\end{array}$ & $<0.001$ & $\begin{array}{l}1.79 \\
(0.86, \\
3.73)\end{array}$ \\
\hline CRB65 $5^{\text {high,f }}$ & $\begin{array}{l}3.72 \\
(1.53, \\
9.01)\end{array}$ & 0.004 & $\begin{array}{l}3.91 \\
(0.89 \\
17.08)\end{array}$ & 0.07 & $\begin{array}{l}3.61 \\
(1.52, \\
8.57)\end{array}$ & 0.004 & $\begin{array}{l}4.70 \\
(1.93, \\
11.42)\end{array}$ & 0.001 & $\begin{array}{l}2.83 \\
(1.20, \\
6.69)\end{array}$ \\
\hline $\begin{array}{l}\text { SIRS } \\
\text { high }\end{array}$ & $\begin{array}{l}2.72 \\
(1.14, \\
6.47)\end{array}$ & 0.024 & $\begin{array}{l}0.80 \\
(0.15, \\
4.14)\end{array}$ & 0.788 & $\begin{array}{l}2.78 \\
(1.28, \\
6.06)\end{array}$ & 0.010 & $\begin{array}{l}5.14 \\
(2.18, \\
12.12)\end{array}$ & $<0.001$ & $\begin{array}{l}1.58 \\
(0.70, \\
3.56)\end{array}$ \\
\hline qSOFA ${ }^{\text {high }}$ & $\begin{array}{l}3.19 \\
(1.17, \\
8.70)\end{array}$ & 0.023 & $\begin{array}{l}2.99 \\
(0.66, \\
13.51)\end{array}$ & 0.156 & $\begin{array}{l}1.68 \\
(0.66, \\
4.29)\end{array}$ & 0.275 & $\begin{array}{l}2.37 \\
(0.87 \\
6.40)\end{array}$ & 0.09 & $\begin{array}{l}1.95 \\
(0.70, \\
5.46)\end{array}$ \\
\hline
\end{tabular}

${ }^{a}$ Severe outcome is defined as receiving intensive care treatment and/or having all of the following three factors: pneumonia on admission + receiving oxygen supplementation during the hospital stay + staying [?] 5 days in hospital

${ }^{\mathrm{b}}$ Adjusted odds ratio

${ }^{\mathrm{c}}$ Logistic regression analyses. Adjusted for age, sex and having [?]2 predisposing conditions

${ }^{\mathrm{d}}$ Linear regression analysis: results given as regression coeffiecient (95\% CI for the regression coefficient)

${ }^{\mathrm{e}} 6$ patients did not have an airway sample for bacterial culture

${ }^{\mathrm{f}}$ Not adjusted for age, as age is part of the score

Table 4. Antiviral and antibiotic treatment and associations with patient characteristics, laboratory data, clinical risk scores and clinical outcomes

\begin{tabular}{lllll}
\hline & $\begin{array}{l}\text { Antimicrobial } \\
\text { treatment }\end{array}$ & $\begin{array}{l}\text { Antimicrobial } \\
\text { treatment }\end{array}$ & $\begin{array}{l}\text { Antimicrobial } \\
\text { treatment }\end{array}$ & $\begin{array}{l}\text { Antimicrobial } \\
\text { treatment }\end{array}$ \\
\hline & Antiviral & Antiviral & Antibiotic & Antibiotic \\
treatment & treatment & treatment & treatment \\
Patients, $\mathrm{n}(\%)$ & $58(37.2)$ & $58(37.2)$ & $121(77.6)$ & $121(77.6)$
\end{tabular}




\begin{tabular}{|c|c|c|c|c|}
\hline & $\begin{array}{l}\text { Antimicrobial } \\
\text { treatment }\end{array}$ & $\begin{array}{l}\text { Antimicrobial } \\
\text { treatment }\end{array}$ & $\begin{array}{l}\text { Antimicrobial } \\
\text { treatment }\end{array}$ & $\begin{array}{l}\text { Antimicrobial } \\
\text { treatment }\end{array}$ \\
\hline & $\begin{array}{l}\operatorname{adjOR}^{\mathrm{a}}(95 \% \\
\mathrm{CI})^{\mathrm{b}}\end{array}$ & $\mathrm{P}$ value & $\operatorname{adjOR}(95 \% \mathrm{CI})^{\mathrm{b}}$ & $\mathrm{P}$ value \\
\hline \multicolumn{5}{|l|}{$\begin{array}{l}\text { Patient } \\
\text { characteristics }\end{array}$} \\
\hline Age [cont. $]^{\mathrm{c}}$ & $0.99(0.98,1.01)$ & 0.491 & $1.00(0.98,1.02)$ & 0.965 \\
\hline Females & $1.28(0.66,2.47)$ & 0.467 & $1.45(0.68,3.10)$ & 0.339 \\
\hline $\begin{array}{l}{[?] 2 \text { predisposing }} \\
\text { conditions } \\
\text { Laboratory data }\end{array}$ & $0.85(0.42,1.71)$ & 0.648 & $1.24(0.55,2.77)$ & 0.607 \\
\hline $\begin{array}{l}\mathrm{CRP}(\mathrm{mg} / \mathrm{L}) \text { on } \\
\text { admission [cont.] }\end{array}$ & $1.00(0.99,1.00)$ & 0.367 & $1.04(1.02,1.06)$ & $<0.001$ \\
\hline $\begin{array}{l}\text { Bacterial findings } \\
\text { on admission }{ }^{\mathrm{d}} \\
\text { Clinical risk } \\
\text { scores }\end{array}$ & $0.69(0.34,1.41)$ & 0.311 & $3.18(1.22,8.32)$ & 0.018 \\
\hline CRB high & $1.36(0.68,2.74)$ & 0.382 & $2.07(0.86,5.03)$ & 0.106 \\
\hline $\mathrm{CRB}^{\mathrm{e}}{ }^{\mathrm{e}}$ high & $0.96(0.41,2.23)$ & 0.929 & $2.85(0.89,9.14)$ & 0.078 \\
\hline SIRS high & $2.19(1.03,4.66)$ & 0.041 & $3.03(0.99,9.31)$ & 0.053 \\
\hline $\begin{array}{l}\text { qSOFA high } \\
\text { Clinical outcomes }\end{array}$ & $0.33(0.11,1.04)$ & 0.059 & $6.87(0.88,53.30)$ & 0.065 \\
\hline Severe outcome $e^{f}$ & $1.33(0.59,3.00)$ & 0.488 & $3.77(1.05,13.48)$ & 0.041 \\
\hline $\begin{array}{l}\text { Intensive care } \\
\text { treatment }\end{array}$ & $4.23(0.99,18.09)$ & 0.050 & $0.95(0.18,4.89)$ & 0.992 \\
\hline Pneumonia & $1.05(0.54,2.05)$ & 0.877 & $5.06(2.02,12.68)$ & 0.001 \\
\hline $\begin{array}{l}\text { Oxygen } \\
\text { supplementation }\end{array}$ & $1.81(0.89,3.66)$ & 0.100 & $4.12(1.61,10.58)$ & 0.003 \\
\hline [?]5 days in hospital & $0.85(0.42,1.74)$ & 0.663 & $2.67(1.13,6.34)$ & 0.025 \\
\hline
\end{tabular}

${ }^{a}$ Adjusted odds ratio

${ }^{\mathrm{b}}$ Logistic regression analyses. Adjusted for age, sex and having [?]2 predisposing conditions

${ }^{\mathrm{c}}$ Linear regression analysis: results given as regression coefficient (95\% CI for the regression coefficient)

${ }^{\mathrm{d}} 6$ patients did not have an airway sample for bacterial culture

${ }^{\mathrm{e}}$ Not adjusted for age, as age is part of the score

${ }^{\mathrm{f}}$ Severe outcome is defined as receiving intensive care treatment and/or having all of the following three factors: pneumonia on admission + receiving oxygen supplementation during hospital stay + staying [?]5 days in hospital

Figure legends

Figure 1

Symptoms, clinical risk scores and outcomes of disease and according to influenza (sub)types

A) Percentage of patients self-reporting specific symptoms prior to admission B) Percentage of patients with high clinical risk scores at admission defined by CRB, CRB65, SIRS and qSOFA criteria. C) Percentage of patients with various clinical outcomes of disease. Severe outcome is defined as receiving intensive care 
treatment and/or having all of the following three factors: pneumonia on admission + receiving oxygen supplementation during hospital stay + staying [?]5 days in hospital.

Oxygen=oxygen supplementation and ICU $=$ Intensive care unit. ${ }^{*}$ indicates $p<0.05$ and $* *$ indicates $\mathrm{p}<0.01$ (chi2 analyses).

Figure 2

\section{Use of antimicrobial treatment according to influenza season and influenza (sub)types}

A) Percentage of patients receiving antiviral and antibiotic treatment over the 4 consecutive influenza seasons. For each treatment type, season 1 is compared with the other seasons. B) Percentage of patients receiving antiviral and antibiotic treatment according to their influenza (sub)types. *indicates $p<0.05$ and ** indicates $\mathrm{p}<0.01$ (chi2 analyses).

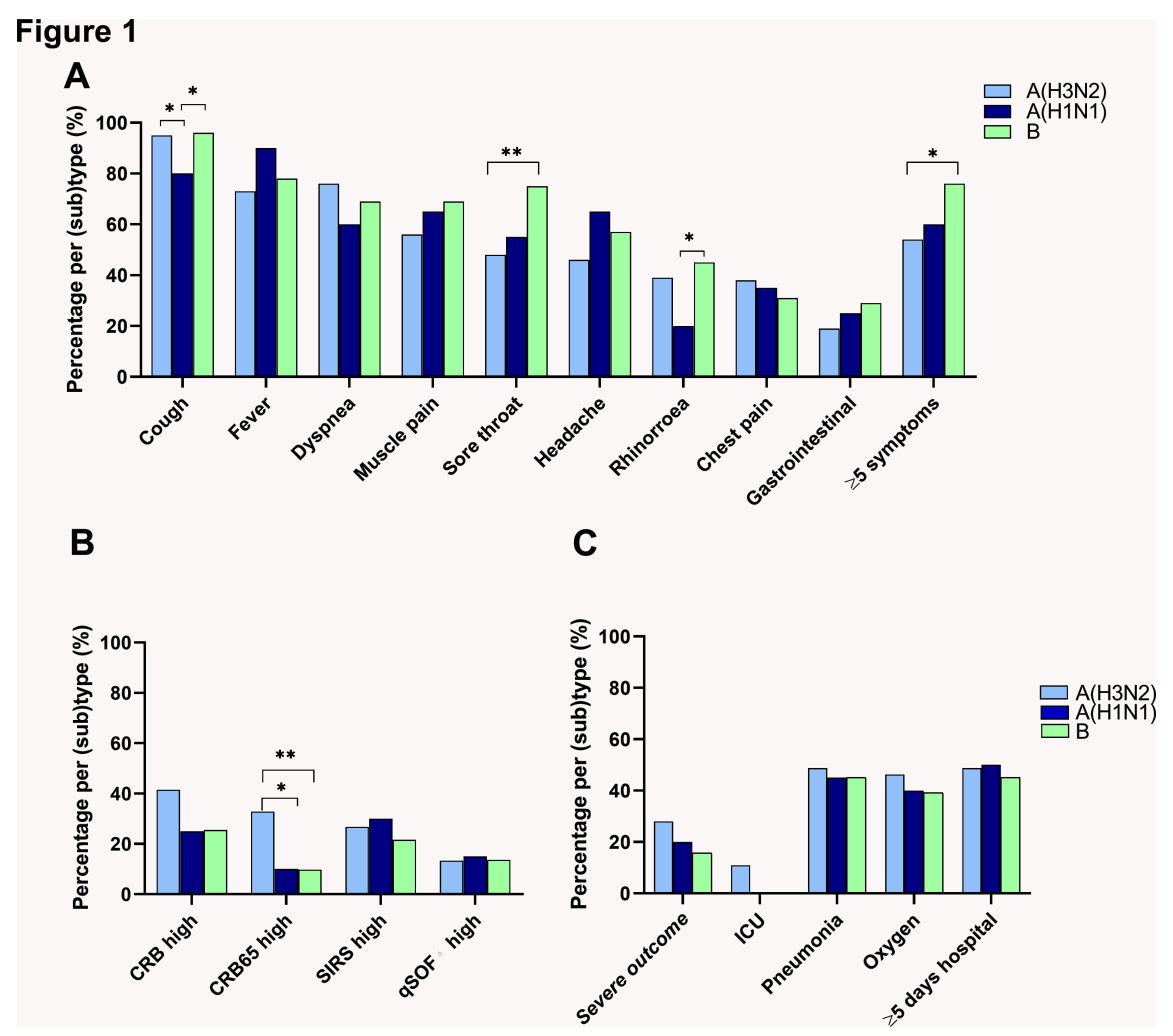


Figure 2

A

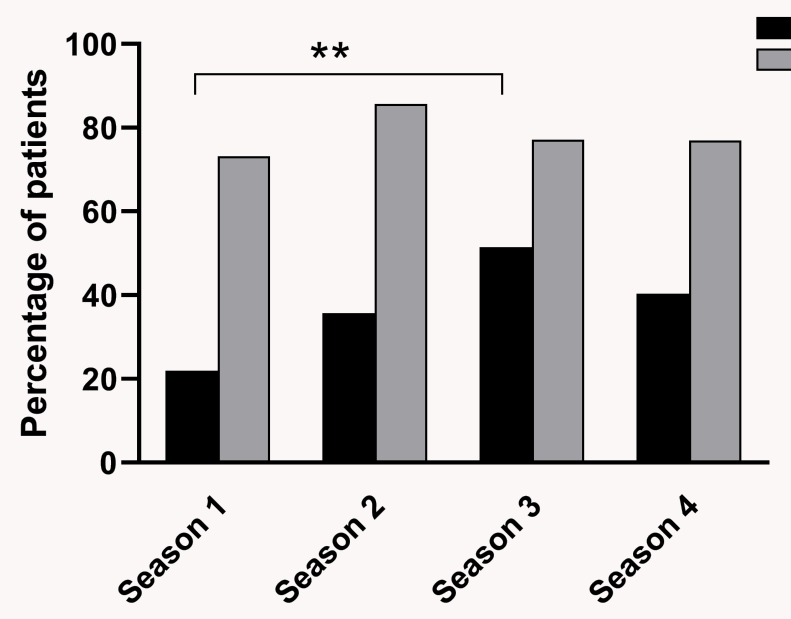

Antiviral treatment

Antibiotic treatment

B

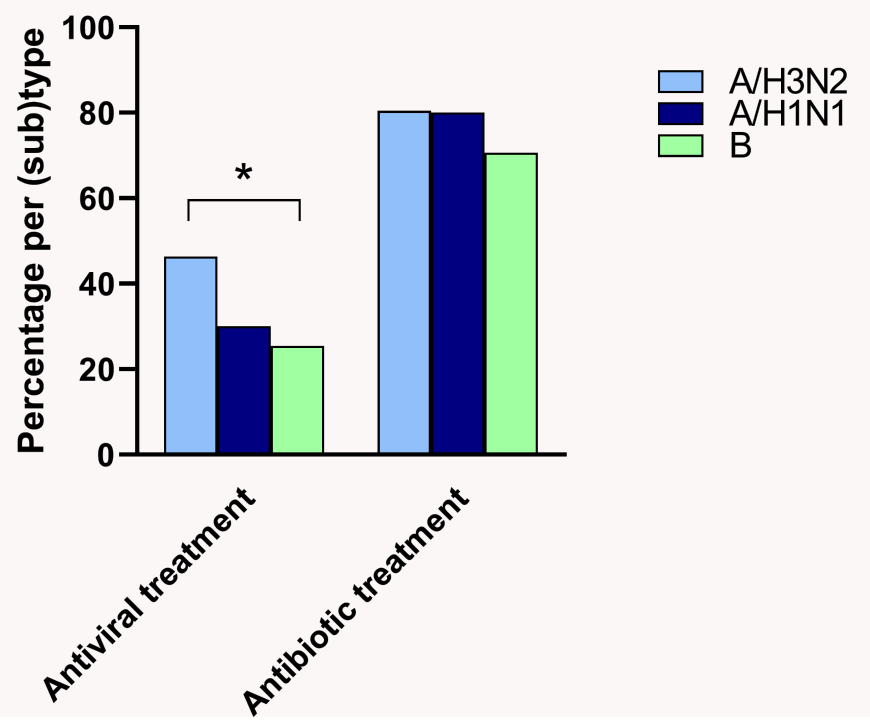

